DOI: $\underline{10.20472 / E S .2015 .4 .3 .005}$

\title{
THE ROLE OF FDI IN FOSTERING EXPORTS FROM THE HOST COUNTRY
}

\section{PAVLA VOZÁROVÁ}

\begin{abstract}
:
In this paper, I propose a theoretical model analyzing the impact of FDI on exports from the host country. Using the framework of monopolistic competition with heterogenous firms, I show that the entry of highly efficient MNEs increases competition in the export market, which leads to crowding-out of domestic exporters. As a result, even though overall efficiency of the industry increases, exports by this industry may decrease.

Further on, I add into my model a potential spillover effect that FDI can induce by lowering costs associated to export activities for all firms. I show that in such situation, the increased efficiency is more likely to outweigh the negative competition effect, resulting in larger exports from the host country.
\end{abstract}

\section{Keywords:}

FDI, MNE, spillovers, exports

JEL Classification: F23

\section{Authors:}

PAVLA VOZÁROVÁ, University of Economics, Prague, Czech Republic, Email: pavla.vozarova@vse.cz

\section{Citation:}

PAVLA VOZÁROVÁ (2015). The Role of FDI in Fostering Exports from the Host Country. International Journal of Economic Sciences, Vol. IV(3), pp. 94-114., 10.20472/ES.2015.4.3.005 


\section{Introduction}

Foreign direct investment (FDI) is an operation through which a multinational enterprise (MNE) acquires substantial control over a domestic firm in the target economy. FDI can be realized in several ways, from which the literature distinguishes mainly between takeovers, where the foreign capital enters an existing domestic company, and greenfield projects, where a new firm is created with foreign capital. Under both of these arrangements, net investment inflows nowadays represent several percent of GDP in both developed and developing countries and sales of the biggest MNEs are larger than the GDP of many developed economies. In Central and Eastern Europe particularly, the volume of FDI has been increasing over the past twenty five years, and it has been seen as one of the factors which are significantly reshaping the economies in transition from a centrally planned to a market system. It has generally been welcomed and even promoted by domestic governments, and the debate among policy makers about how to attract foreign investors is still ongoing.

In the academic environment, there is also an ongoing debate about FDI, trying to understand what the impact of the presence of MNEs is in the domestic market and what the different ways are in which it can be beneficial to the host economy. Several arguments have been made in favor or against FDI, and many questions are yet unresolved. In this paper, my aim is to contribute to this debate by studying the role of FDI in fostering exports from the host country.

It is well known (see e.g. Cohen, 2007) that many FDI projects are motivated not by the need to serve the market of the host country only, but rather by the need to find an export platform from which the MNE can serve the whole neighborhood region. This is especially true in Central and Eastern Europe, where countries are mostly small and open economies and exports and imports as shares of GDP are very large. It is therefore expected that when an MNE comes to a country, a significant part of its production is being exported. What is less clear is how exports by other firms in the domestic economy are affected in such situation, which is what I study in this paper.

Using the model of monopolistic competition with heterogenous firms, I show that a shock to the host country equlibrium, represented by a highly efficient MNE, does not have to be only positive for domestic firms. Unlike many papers dealing with similar issue, I consider the fact that this MNE can induce a very high competition level in the export market for domestic exporters, which may force them to decrease their production. On the other hand, I also show that under some conditions, the impact of FDI can be positive for overall exports from the host country, since general efficiency of the exporting industry increases. Moreover, I also show that even individual domestic exporters can be made 
better off if the presence of MNEs induces export spillovers, i.e., positive externalites stemming from the activity of MNEs that lower obstacles to trade (mostly on the costs side) for domestic firms as well.

\section{Literature review}

There are several papers which discuss the impact of incoming FDI on export performance of domestic firms. As stated by Koenig et al. (2010), they are mostly empirical and they do not really provide a more sophisticated theoretical model that would explain the mechanism of the impact of FDI on host country exports. Some of them base their econometric specification on formal theoretical considerations, and these can be broadly classified into two streams according to the role that FDI spillovers play in the model. The first stream, represented by Aitken et al. (1997) or Greenaway et al. (2004), sees the spillover as an externality that decreases the costs related to exporting activities of domestic firms. The second stream, represented by Fernandes and Tang (2014), sees the spillover (coming not only from an MNE but from any exporting firm in the industry) as a signal about the demand in the foreign market, reducing thus the uncertainty of a firm that decides whether to export or not.

In my paper, I am inspired rather by the first stream and I see the spillover effect as a cost-reducing externality. However, I do not limit the role of MNEs only to be a potential source of spillovers but I consider also their other possible impact on domestic firms that is given by a change in competition level induced by the presence of such MNEs and by their activies in the export market. There are several papers among those that study the overall impact of FDI on productivity of domestic firms that show why when talking about this issue, both the potential spillover effect and the changing market structure effect should be taken into account. Kosova (2010) discusses this problem in the case of intraindustry dynamics, where the spillover can be offset by increased competition level, and Javorcik and Spatareanu (2005) discuss it in the case of inter-industry dynamics, where the spillover can be strenghtened by increased demand for intermediary goods. However, papers that deal with the impact of FDI on domestic firms' exports do not take the changing market structure into account, which, in my opinion, undermine the precision of their results.

My goal is thus to propose a theoretical model that would describe the interaction between the spillover effect and the changing market structure effect. To describe the changing market structure, I build on Markusen and Venables (1999) model, but I accomodate it to capture the effects that I want to study.

Markusen and Venables (1999) use a "one country two goods" model and they analyse how the inflow of FDI in the sector of consumer goods affects suppliers of 
intermediary goods. The authors argue that if the number of MNEs in the upstream sector increases, some domestic firms from that particular sector are crowded out from the market, because MNEs are more efficient and increase the competition within the sector. Incoming MNEs rise the demand for intermediary goods, but the crowding out of domestic firms has an opposite effect and overall, the demand created by MNEs may or may not offset the loss of demand by domestic firms that have been crowded out.

In my paper, I use a "two countries one good model" and I study how the inflow of FDI affects exports of individual domestic firms in the industry and overall exports from the whole industry. I also describe the crowding-out effect given by increased competition and I show that even though incoming MNEs can increase overall exports, the crowdingout effect may have an opposite impact and the two effects may offset each other. It is only after I describe this mechanism of changing market structure that I add in my model a potential spillover effect and I explain its impact on the resulting equilibrium of my model.

\section{Model}

\subsection{Geography and industry structure}

In my model, the world is composed only of two countries, which I will refer to as the Home country and the Foreign country. There is only one industry, i.e., there is only one good that is being produced, consumed and traded. The Home country is the country in which production takes place, both countries together represent the world demand for the good that is being produced. There is trade between the two countries, the trade flow goes in one direction - from the Home country to the Foreign country. Originally, there are only domestic firms that operate in the Home country, but then more efficient MNEs open their subsidiaries there. As well as domestic firms, MNEs can produce for home or for foreign market, under conditions that will be specified later on.

This is a very simple setup, whose purpose is to model the situation of a geographic region where the production takes place in one country and is exported abroad. The MNEs that enter in the Home country are supposed to orginate from outside of the region, and it is supposed that only after their entry the region can be served by their products (e.g. because of excessive trasportation costs that would make trade flow from outside the region inefficient). The main question that is addressed by the model is how the entry of such MNEs influences exports from the Home country to the rest of the region (i.e., to the Foreign country).

To describe the market structure within the industry that is being studied, I use the Dixit and Stiglitz (1977) model of monopolistic competition. This means that there is a continuum of firms within the sector, each produces a variety of the given good and each behaves as monopolist over that variety, i.e., each firms maximizes its profits by choosing 
the price of the variety it is producing. All varieties are substitutes, and the industry can be characterized by the overall price index $q$, that combines prices $p$ of varieties $\omega$ and their elasticity of substitution $\varepsilon$ :

$$
q=\left(\int_{\omega \in \Omega} p^{1-\varepsilon}(\omega) \mathrm{d} \omega\right)^{\frac{1}{1-\varepsilon}},
$$

where $\Omega$ is the set of all available varieties. Even though each firm choses the price for its product, it is considered to be too small to influence the overall price index.

The prices that firms chose depend on their efficiency. Similarly as in the model of Melitz (2003), I allow in my model firms to have different degree of efficiency defined in the following way: a more efficient firm has lower marginal costs. For the sake of simplicity, only marginal costs differ across firms, and so all firms have the same fixed costs. Marginal costs (and thus the efficiency level) are denoted by $\varphi \in[\underline{\varphi}, \bar{\varphi}]$, where $\underline{\varphi}>0$. Hence, lower $\varphi$ means higher efficiency. The level of efficiency determines the price that the firm sets for its product, the amount produced, and hence also its profits, as we will see later. There is a cutoff level of efficiency which I denote $\varphi^{*}$ - firms with $M C>\varphi^{*}$ are too inefficient to have non-negative profits and they have to exit the market. I assume that $\varphi^{*} \in[\underline{\varphi}, \bar{\varphi}]$. This cutoff level allows me to write the price index $q$ as

$$
q=\left(\int_{\underline{\varphi}}^{\varphi^{*}} p^{1-\varepsilon}(\varphi) \mathrm{d} \varphi p^{1-\varepsilon}(\varphi) \mathrm{d} \varphi\right)^{\frac{1}{1-\varepsilon}}
$$

where $\varepsilon>1$ is the elasticity of substitution between the varieties of the good.

Similarly as in Markusen and Venables (1999), the demand with respect to the price index is modeled as $C q^{-\eta}$, where $C$ and $\eta$ are constants such that $C>0$ and $1<\eta<\varepsilon$. For the sake of simplicity, I assume there is the same demand in the two countries, which means that the two countries are assumed to be of the same size and sharing the same preferences, bus as we will see later, none of this changes anything on the implications of the model.

Each firm that is in the market is producing the amount $x_{d}$ for the domestic market, some of them can produce also the amount $x_{e}$ for export. The reason for which not all firms export is the existence of transportation costs and fixed cost of exporting. Transportation costs, modelled as iceberg costs, represent unit costs of selling in the foreign market, which may be due to transport and tariffs. Fixed costs of exporting are due to all fixed expenses (foreign market research, finding and keeping trade partners, etc.) that the firm that exports may face. 
The existence of transportation costs also implies that price of the same variety has to be higher when the variety is sold in the foreign market. I denote by $p_{d}$ and $p_{e}$ prices of a variety when sold in the domestic and in the foreign market respectively. The difference in prices and the fact that not all firms export imply that in equilibrium, we will have two values of the overall price index $q$, which will be $q_{d}$ for the domestic market and $q_{e}$ for the foreign market.

From the Dixit-Stiglitz model, we know that the demand $x$ for each variety that has the price $p$ is

$$
x=p^{-\varepsilon} C q^{\varepsilon-\eta} .
$$

When we separate this for the two markets, we get

$$
x_{d}=p_{d}^{-\varepsilon} C q_{d}^{\varepsilon-\eta}
$$

for the comestic market and

$$
x_{e}=p_{e}^{-\varepsilon} C q_{e}^{\varepsilon-\eta}
$$

for the foreign market.

The profit of a firm with efficiency level $\varphi$ is defined as

$$
\pi=\pi_{d}+\pi_{e}
$$

where I denote by $\pi_{d}$ the profit from serving the domestic market and $\pi_{e}$ the profit from serving the foreign market. Given the cost structure, the two profits can be separately expressed as

$$
\pi=p_{d} x_{d}-\varphi x_{d}-F_{d} \text { and } \pi_{e}=p_{e} x_{e}-\varphi \tau x_{e}-F_{e}
$$

where fixed costs $F_{d}$ and $F_{e}$ are associated with production for domestic and foreign market respectively, and we assume $F_{d}<F_{e}{ }^{1}$. The variable $\tau>1$ in the export profit expression represents iceberg transportation costs.

In this monopolistic competition model with two separate countries, firms maximize their profits with respect to prices $p_{d}$ and $p_{e}$. From such profit maximization, we obtain that

$$
p_{d}=\alpha \varphi \text { and } p_{e}=\alpha \tau \varphi
$$

\footnotetext{
${ }^{1}$ Since, as we will see later, only firms that produce for domestic market can also become exporters, we can perceive $F_{e}$ as additional fixed costs of exporting.
} 
where $\alpha=\frac{\varepsilon}{\varepsilon-1}>1$.

Given these prices, the amounts produced by the firm are

$$
x_{d}=(\alpha \varphi)^{-\varepsilon} C q_{d}^{\varepsilon-\eta} \text { and } x_{e}=(\alpha \varphi \tau)^{-\varepsilon} C q_{e}^{\varepsilon-\eta}
$$

The profit of the firm from serving the domestic market is

$$
\pi_{d}=(\alpha-1) \alpha^{-\varepsilon} \varphi^{1-\varepsilon} C q_{d}^{\varepsilon-\eta}-F_{d},
$$

the profit from serving the foreign market is

$$
\pi_{e}=\tau^{1-\varepsilon}(\alpha-1) \alpha^{-\varepsilon} \varphi^{1-\varepsilon} C q_{e}^{\varepsilon-\eta}-F_{e} .
$$

Simple comparative statics show that $\frac{\partial p_{e}}{\partial \varphi}>0, \frac{\partial p_{d}}{\partial \varphi}>0, \frac{\partial x_{d}}{\partial \varphi}<0, \frac{\partial x_{e}}{\partial \varphi}<0, \frac{\partial \pi_{d}}{\partial \varphi}<0$ and $\frac{\partial \pi_{e}}{\partial \varphi}<$, which means that companies with higher efficiency (lower $\varphi$ ) set lower prices, produce larger amounts of output and achieve higher profits. We can also see that since $\tau>1, \varepsilon>1$ and $F_{e}>F_{d}$, not all firms that are able to produce for the domestic market and get non-zero profit there can do so in the foreign market. This shows that only more efficient firms will serve both domestic and foreign market, as mentioned earlier.

\subsection{Equilibrium conditions}

There are several conditions that characterize the equlibrium in this model, which is defined by price indices levels and the number of firms that operate in both markets.

The number of firms is given by zero-profit conditions that define the cut-off efficiency. Firms with lower efficiency cannot operate in the market at all or can serve only the domestic market but cannot export. In other worlds, the number of firms is rather defined as two intervals of efficiency that can be observed in the market within the above mentioned interval $[\underline{\varphi}, \bar{\varphi}]$. There are more efficient firms that can serve both the domestic and the foreign market, these have efficiency $\varphi \in\left[\underline{\varphi}, \varphi^{*}\right]$. There are less efficient firms that can serve only the domestic market, these have efficiency $\varphi \in\left[\varphi^{*}, \tilde{\varphi}\right]$. Firms with efficiency $\varphi \in[\tilde{\varphi}, \bar{\varphi}]$ cannot operate in none of the markets.

These cut-off efficiencies are characterized by zero-profit conditions

$$
\pi_{d}(\tilde{\varphi})=(\alpha-1) \alpha^{-\varepsilon} \tilde{\varphi}^{1-\varepsilon} C q_{d}^{\varepsilon-\eta}-F_{d}=0
$$

for the cut-off efficiency $\tilde{\varphi}$ and

$$
\pi_{e}\left(\varphi^{*}\right)=\tau^{1-\varepsilon}(\alpha-1) \alpha^{-\varepsilon} \varphi^{* 1-\varepsilon} C q_{e}^{\varepsilon-\eta}-F_{e}=0
$$


for the cut-off efficiency $\varphi^{*}$.

Price indices levels are defined by

$$
q_{d}=\left(\int_{\underline{\varphi}}^{\tilde{\varphi}} p_{d}^{1-\varepsilon}(\varphi) \mathrm{d} \varphi\right)^{\frac{1}{1-\varepsilon}}
$$

and

$$
q_{e}=\left(\int_{\underline{\varphi}}^{\varphi^{*}} p_{e}^{1-\varepsilon}(\varphi) \mathrm{d} \varphi\right)^{\frac{1}{1-\varepsilon}}
$$

All these conditions represent four equations for four variables $q_{d}, q_{e}, \tilde{\varphi}$ and $\varphi^{*}$ that define the equilibrium.

Since the conditions that define the equilibrium are separated for the domestic and for the foreign market, and since in this paper, I am purely interested in exports, from now on, I will consider only the foreign market, keeping in mind that the production of the goods takes place in the Home country. Overall exports from the Home to the Foreign country can be then written as

$$
E=\int_{\underline{\varphi}}^{\varphi^{*}} x_{e}(\varphi) \mathrm{d} \varphi .
$$

In the next section, we will see how these equilibrium exports change when more efficient MNEs enter and start to produce in the domestic market.

\subsection{Impact of the inflow of FDI on equilbrium}

The purpose of this paper is to determine how the inflow of FDI in the Home country influences exports to the Foreign country. By the inflow of FDI, I mean the increase in the number of multinational firms operating in the industry. In the paper, I associate the number of exporting firms in the industry with the length of the interval $\left[\varphi, \varphi^{*}\right]$ : the larger this interval is, the more firms there are. Up to now, I considered the lower bound $\underline{\varphi}$ to be fixed and I defined the conditions that define the value of $\varphi^{*}$, assuming that there is a given mass of firms and the only issue is to determine the cutoff efficiency above which the firms cannot be exporters under the given conditions. 
However, when I model the inflow of FDI given by MNEs, I follow a different logic. I assume that MNEs are firms with very high efficiency levels: this fact is theoretically supported by Melitz (2003) and further proven by several empirical analyses. Following the same approach as Kosova (2010), I suppose that when an MNE enters the market, it has higher efficiency than any of the domestic competitors: this means that the distribution of the efficiency of firms operating in the domestic market is shifted towards higher levels by the entry of a MNE. In this paper, I model this change as a shift of the efficiency lower bound $\underline{\varphi}$. More precisely, an increase in the number of multinational firms in the industry results in lower $\underline{\varphi}$, which signals that more efficient firms are now operating in the market.

I would like to see how such change influences overall exports from the Home country, more specifically, whether exports increase or decrease after the entry of MNEs. Therefore, I am searching for the sign of the derivative

$$
\frac{\mathrm{d} E}{\mathrm{~d} \underline{\varphi}}
$$

where exports $E$ are defined by (4). Recalling that higher efficiency means lower $\varphi$, the entry of MNEs in my model means that $\underline{\varphi}$ decreases. Hence, the increase of exports due to MNEs would correspond to a negative sign of the derivative (5), whereas the decrease of exports would correspond to a positive sign of (5).

Determining the sign of (5) is not trivial. Obviously, any change in $\underline{\varphi}$ has to result in a change of the equilibrium cutoff level $\varphi^{*}$ and of the price index $q_{e}$, since $\underline{\varphi}$ is one of the parameters of the equilibrium conditions. As we can see from (2), the price index $q_{e}$ determines the level of exported amount $x_{e}$ for each firm and hence, the derivative (5) should be written properly as

$$
\frac{\mathrm{d} E}{\mathrm{~d} \underline{\varphi}}=\frac{\mathrm{d}}{\mathrm{d} \varphi}\left(\int_{\underline{\varphi}}^{\varphi^{*}(\underline{\varphi})} x_{e}(\varphi, \underline{\varphi}) \mathrm{d} \varphi\right) .
$$

Using the Leibniz theorem, we can write

$$
\frac{\mathrm{d} E}{\mathrm{~d} \underline{\varphi}}=x_{e}\left(\varphi^{*}\right) \frac{\mathrm{d} \varphi^{*}}{\mathrm{~d} \underline{\varphi}}-x_{e}(\underline{\varphi})+\int_{\underline{\varphi}}^{\varphi^{*}} \frac{\partial x_{e}}{\partial \underline{\varphi}} \mathrm{d} \varphi
$$


Let us consider this expression. For its analysis, we will first state three lemmas that will help us to explain its intuitive meaning and to describe what are the different ways in which FDI inflow affects export. The proofs of all three lemmas are presented in Appendix.

Lemma 1. For all values of parameters of the model, it always holds that

$$
\frac{\mathrm{d} \varphi^{*}}{\mathrm{~d} \underline{\varphi}}>0 .
$$

Lemma 2. For all values of parameters of the model, it always holds that

$$
x_{e}\left(\varphi^{*}\right) \frac{\mathrm{d} \varphi^{*}}{\mathrm{~d} \underline{\varphi}}-x_{e}(\underline{\varphi})<0 .
$$

Lemma 3. For all values of parameters of the model, it always holds that

$$
\int_{\underline{\varphi}}^{\varphi^{*}} \frac{\partial x_{e}}{\partial \underline{\varphi}} \mathrm{d} \varphi>0 .
$$

Let us now explain the intuitive meaning of these mathematical expressions. Lemma 1 tells us that when the lower bound of the efficency interval $\left[\underline{\varphi}, \varphi^{*}\right]$, decreases, the upper bound decreases as well and hence the whole interval shifts to the left towards higher efficiency. This means that when more efficient firms (MNEs in this case) enter the market, some of the least efficient firms that were operating in the market so far cannot stand the competition and they are crowded out. This effect, discussed and model in different ways in many papers (e.g. Melitz, 2003; Kosova, 2010), is of course unpleasant for firms that are being crowded out, but it is beneficial for the industry, whose overall efficiency improves. More efficient firms produce more goods to export (all else being kept constant) and this is why the shift of efficiency interval has a positive effect on exports. This positive effect is described by Lemma 2 which tells us that the two first terms of expression (7) are negative, i.e. with decreasing $\underline{\varphi}$ exports increase.

On the other hand, as shown by Lemma 3, the third term of expression (7) is positive, i.e., with decreasing $\underline{\varphi}$ exports decrease. The proof (presented in Appendix) is mostly based on the fact that the inflow of more efficient firms (decreasing $\underline{\varphi}$ ) decreases the prices and also the price index $q_{e}$, which, in turn, decreases exports of all firms in the market and their profits. This mechanism also explains why the crowding-out effect mentioned above takes place.

To sum up, there are two contradictory effects of FDI inflows. On the one hand, more efficient firms are operating in the market and this should increase exports, but at the same time, these more efficient firms induce tougher competition in the foreign market, 
which decreases exports. The final effect depends on the parameters of the model, but there is one prediction we can make about it. This prediction is stated in the following theorem, whose proof is provided in Appendix :

Theorem 1. When the elasticity of substitution among the varieties of the exported good is close enough to the elasticity of demand for these goods, then the entry of multinational firms in the industry will increase overall exports:

$$
\frac{\mathrm{d} E}{\mathrm{~d} \underline{\varphi}}<0 \quad \text { if } \quad \varepsilon \rightarrow \eta .
$$

The meaning of this theorem is rather straightforward. If the elasticity of substitution is close enough to the elasticity of demand, it means that there is not so much competition between the varieties of the good. In such situation, the crowding-out effect is not so strong because firms do not compete that fiercly. As a result, the crowding-out effect does not outweight the fact that more efficient firms are in the market, which produce higher amount of exports.

\subsection{Effect of spillovers}

So far, I have discussed two channels through which the inflow of FDI influences overall exports from the host country - the shift in efficiency level (having a positive effect on exports) and the crowding-out effect (having a negative impact on exports). However, following the literature, I should also consider a possible third channel. The activity of MNEs in the host country is often supposed to induce technological spillovers on domestic firms. These spillovers are a positive externality that makes it easier for the domestic firms to export.

In my model, such externality can be described in two ways. First, the presence of MNEs can lower transportation costs $\tau$ - transport can become less expensive because of economies of scale, tariffs may be reduced because of MNEs' lobbying, etc ${ }^{2}$. Second, the presence of MNEs can lower fixed costs of exporting $F_{e}$ - foreign customers of MNEs are used to consume the good that is being exported and keeping contact with the market can be then easier also for domestic exporters, etc. Since the presence of MNEs makes the lower bound of efficiency $\underline{\varphi}$ to decrease and this is supposed to lower the costs, the spillower effect can be modelled as

\footnotetext{
${ }^{2}$ Note also that because of the iceberg definition of transportation costs (multiplying the marginal costs), such spillover effect can be alternatively explained as a technological spillover that decreases marginal costs of domestic companies, making them more efficient.
} 


$$
\frac{\mathrm{d} \tau(\underline{\varphi})}{\mathrm{d} \underline{\varphi}}>0 \text { and / or } \frac{\mathrm{d} F_{e}(\underline{\varphi})}{\mathrm{d} \underline{\varphi}}>0 .
$$

Of course, the presence of MNEs can lower both transaportation and fixed costs. I will consider both situations separately, but I will show that their effects are of the same sing. Therefore, it is clear that the impact is even stronger when both of them occur. The effect of both types of spillower is summarized in the following theorems, whose proofs is provided in Appendix.

Theorem 2. Let us model the spillover effect by $\frac{d \tau(\underline{\varphi})}{d \underline{\varphi}}>0$. When we denote by $E$ overall exports disregarding the possible spillover effect and by $E_{S}$ overall exports taking into account the spillover effect is, then for all values of the parameters of the model, it holds that

$$
\frac{\mathrm{d} E_{S}}{\mathrm{~d} \underline{\varphi}}<\frac{\mathrm{d} E}{\mathrm{~d} \underline{\varphi}} .
$$

Theorem 3. Let us model the spillover effect by $\frac{d F_{e}(\underline{\varphi})}{d \underline{\varphi}}>0$. When we denote by $E$ overall exports disregarding the possible spillover effect and by $E_{s}$ overall exports taking into account the spillover effect is, then for all values of the parameters of the model, it holds that

$$
\frac{\mathrm{d} E_{S}}{\mathrm{~d} \underline{\varphi}}<\frac{\mathrm{d} E}{\mathrm{~d} \underline{\varphi}} .
$$

The interpretation of the two theorems is straightforward. When we take into account the possiblity of spillover effect, then the same decrease of lower bound efficiency level induces greater increase of exports, which means that the effect of FDI on exports is more positive or at least has greater chance to be positive.

Let me comment briefly on this last finding on my paper. I have shown so far that because of the competition effect, the inflow of FDI may not have the expected positive impact on overall exports and it can even decrease them, because it is decresing exports by individual domestic firms that survive in the market. The last theorem shows that when spillovers occur, the competition effect is dampened and the overall impact of FDI may be less negative or, alternatively, more positive. This is due to the fact that the spillover effect increases exports by individual firms, increasing their efficiency. This means that if existing empirical papers confirm a positive impact of FDI on domestic exporters, they may have been understating the spillover effect, depending on how much the compeition effect (usually unaccounted for in empirical papers) was working in the opposite direction. 


\section{Conclusion}

In this paper, I provide a theoretical framework for studying the impact of FDI on export from the host country, which was so far studied mainly only empirically. I incorporate into this context the problem of domestic firms being crowded out from the foreign market by incoming MNEs, which results in a shift of overall efficiency of the industry, but also in lower exports by surviving domestic firms. I stress this changing market structure because it is so often disregarded in existing literature analyzing export spillovers of FDI.

The main result that I provide in this part of my paper is that even if individual domestic exporters decrease their production because of the competition effect, overall, the presence of new highly efficient MNEs can still result in higher overall exports from the host country. This happens when the elasticity of substitution between varieties of the good that firms produce in this industry is low enough, because then the competition effect is not strong enough to offset the increase in production that is due to the shift in industry efficiency levels.

After describing the negative effect that competition has on domestic exporters, I introduce the possibility of FDI spillovers as an externality that reduces either variable or fixed costs of all exporting firms, including the domestic ones. I prove that such spillovers may offset the negative effect that the increased competition has on domestic exporters and I show that such spillovers strenghten the potential positive effect of FDI on host country exports.

Finally, I discuss why discerning the competition effect and the spillover effect is important for empirical analyses. Since they offset each other in this case, it is not precise to estimate the spillover effect without taking into consideration the competition effect, because in such case, the spillover effect could be underestimated.

\section{References}

Aitken, B., Hanson, G., and Harrison, A. E. (1997). Spillovers, foreign investment, and export behavior. Journal of International economics, 43(1):103-132.

Cohen, S. D. (2007). Multinational Corporations and Foreign Direct Investment: Avoiding Simplicity, Embracing Complexity. Oxford University Press.

Dixit, A. K. and Stiglitz, J. E. (1977). Monopolistic competition and optimum product diversity. The American Economic Review, 67(3): 297-308.

Fernandes, A. P. and Tang, H. (2014). Learning to export from neighbors. Journal of International Economics, 94(1):67-84.

Greenaway, D., Sousa, N., and Wakelin, K. (2004). Do domestic firms learn to export from multinationals? European Journal of Political Economy, 20(4):1027-1043. 
Javorcik, B. and Spatareanu, M. (2005). Disentangling FDI spillover effects: What do firm perception tell us? In T. H. Moran, E. G. and Blomstrom, M., editors, Does Foreign Direct Investment Promote Development? Washington: Institute for International Economics.

Koenig, P., Mayneris, F., and Poncet, S. (2010). Local export spillovers in France. European Economic Review, 54(4):622-641.

Kosova, R. (2010). Do foreign firms crowd out domestic firms? evidence from the Czech Republic. The Review of Economics and Statistics, 92(4):861-881.

Markusen, J. and Venables, A. (1999). Foreign direct investment as a catalyst for industrial development. European Economic Review, 43(2):335-56.

Melitz, M. J. (2003). The impact of trade on intra-industry reallocations and aggregate industry productivity. Econometrica, 71(6):1695-1725. 


\section{Appendix}

Lemma 1. For all values of parameters of the model, it always holds that

$$
\frac{\mathrm{d} \varphi^{*}}{\mathrm{~d} \varphi}>0
$$

Proof. Let us determine $\frac{\mathrm{d} \varphi^{*}}{\mathrm{~d} \underline{\varphi}}$. First, I will use the fact that in equilibrium, the following conditions have to hold:

$$
\pi_{e}\left(\varphi^{*}\right)=\tau^{1-\varepsilon}(\alpha-1) \alpha^{-\varepsilon} \varphi^{* 1-\varepsilon} C q_{e}^{\varepsilon-\eta}-F_{e}=0
$$

and

$$
q_{e}=\left(\int_{\underline{\varphi}}^{\varphi^{*}} p_{e}^{1-\varepsilon}(\varphi) \mathrm{d} \varphi\right)^{\frac{1}{1-\varepsilon}}
$$

From the first condition, we can express

$$
q_{e}=A \varphi^{\frac{\varepsilon-1}{\varepsilon-\eta}}
$$

where $A=\frac{F_{e}^{\frac{1}{\varepsilon-\eta}}}{\left(\tau^{1-\varepsilon}(\alpha-1) \alpha^{-\varepsilon} C\right)^{\frac{1}{\varepsilon-\eta}}}$ is a constant.

In the equilibrium, we have thus

$$
A \varphi^{*} \frac{\varepsilon-1}{\varepsilon-\eta}=\left(\int_{\underline{\varphi}}^{\varphi^{*}} p_{e}^{1-\varepsilon}(\varphi) \mathrm{d} \varphi\right)^{\frac{1}{1-\varepsilon}}
$$

and so we can write an implicit function

$$
F\left(\underline{\varphi}, \varphi^{*}(\underline{\varphi})\right)=A \varphi^{* \frac{\varepsilon-1}{\varepsilon-\eta}}-\left(\int_{\underline{\varphi}}^{\varphi^{*}} p_{e}^{1-\varepsilon}(\varphi) \mathrm{d} \varphi\right)^{\frac{1}{1-\varepsilon}}=0 .
$$

From the Implicit function theorem, we know that

$$
\frac{\mathrm{d} \varphi^{*}}{\mathrm{~d} \underline{\varphi}}=-\frac{\frac{\partial F}{\partial \underline{\varphi}}}{\frac{\partial F}{\partial \varphi^{*}}}
$$


We can derive:

$$
\begin{gathered}
\frac{\partial F}{\partial \underline{\varphi}}=-\frac{1}{1-\varepsilon}\left(\int_{\underline{\varphi}}^{\varphi^{*}} p_{e}^{1-\varepsilon}(\varphi) \mathrm{d} \varphi\right)^{\frac{\varepsilon}{1-\varepsilon}}\left(-p_{e}^{1-\varepsilon}(\underline{\varphi})\right)=\frac{1}{1-\varepsilon} q_{e}^{\varepsilon} p_{e}^{1-\varepsilon}(\underline{\varphi}) \\
\frac{\partial F}{\partial \varphi^{*}}=\frac{\varepsilon-1}{\varepsilon-\eta} A \varphi^{* \frac{\eta-1}{\varepsilon-\eta}}-\frac{1}{1-\varepsilon}\left(\int_{\underline{\varphi}}^{\varphi^{*}} p_{e}^{1-\varepsilon}(\varphi) \mathrm{d} \varphi\right)^{\frac{\varepsilon}{1-\varepsilon}} p_{e}^{1-\varepsilon}\left(\varphi^{*}\right) \\
=\frac{\varepsilon-1}{\varepsilon-\eta} A \varphi^{* \frac{\eta-1}{\varepsilon-\eta}}-\frac{1}{1-\varepsilon} q_{e}^{\varepsilon} p_{e}^{1-\varepsilon}\left(\varphi^{*}\right)
\end{gathered}
$$

Hence, we have

$$
\frac{\mathrm{d} \varphi^{*}}{\mathrm{~d} \underline{\varphi}}=\frac{-\frac{1}{1-\varepsilon} q_{e}^{\varepsilon} p_{e}^{1-\varepsilon}(\underline{\varphi)}}{\frac{\varepsilon-1}{\varepsilon-\eta} A \varphi^{* \frac{\eta-1}{\varepsilon-\eta}}-\frac{1}{1-\varepsilon} q_{e}^{\varepsilon} p_{e}^{1-\varepsilon}\left(\varphi^{*}\right)}
$$

Since $\frac{1}{1-\varepsilon}<0$, the term in the numerator and both the terms in the denominator are positive, which implies that the whole expression is positive and thus concludes the proof.

Lemma 2. For all values of parameters of the model, it always holds that

$$
x_{e}\left(\varphi^{*}\right) \frac{\mathrm{d} \varphi^{*}}{\mathrm{~d} \underline{\varphi}}-x_{e}(\underline{\varphi})<0
$$

Proof. When we plug from (2) $x_{e}=(\alpha \varphi \tau)^{-\varepsilon} C q_{e}^{\varepsilon-\eta}$, we get that

$$
x_{e}\left(\varphi^{*}\right) \frac{\mathrm{d} \varphi^{*}}{\mathrm{~d} \underline{\varphi}}-x_{e}(\underline{\varphi})=(\alpha \tau)^{-\varepsilon} C q_{e}^{\varepsilon-\eta}\left(\varphi^{*-\varepsilon} \frac{\mathrm{d} \varphi^{*}}{\mathrm{~d} \underline{\varphi}}-\underline{\varphi}^{-\varepsilon}\right) .
$$

Since all the terms preceding the parenthesis on the right hand side are positive, it holds that

$$
x_{e}\left(\varphi^{*}\right) \frac{\mathrm{d} \varphi^{*}}{\mathrm{~d} \underline{\varphi}}-x_{e}(\underline{\varphi})<0 \quad \Leftrightarrow \quad \varphi^{*-\varepsilon} \frac{\mathrm{d} \varphi^{*}}{\mathrm{~d} \underline{\varphi}}-\underline{\varphi}^{-\varepsilon}<0 \quad \Leftrightarrow \quad \frac{\mathrm{d} \varphi^{*}}{\mathrm{~d} \varphi}<\frac{\underline{\varphi}^{-\varepsilon}}{\varphi^{*-\varepsilon}}
$$

As shown in the previous proof,

$$
\frac{\mathrm{d} \varphi^{*}}{\mathrm{~d} \varphi}=\frac{-\frac{1}{1-\varepsilon} q_{e}^{\varepsilon} p_{e}^{1-\varepsilon}(\underline{\varphi})}{\frac{\varepsilon-1}{\varepsilon-\eta} A \varphi^{* \frac{\eta-1}{\varepsilon-\eta}}-\frac{1}{1-\varepsilon} q_{e}^{\varepsilon} p_{e}^{1-\varepsilon}\left(\varphi^{*}\right)}
$$


Since $\frac{1}{1-\varepsilon}<0$, the term in the numerator and both the terms in the denominator are positive. This implies that if we omit the first term in the denominator (we make the denominator smaller since we are subtracting a positive term), we make the whole fraction increase:

$$
\frac{\mathrm{d} \varphi^{*}}{\mathrm{~d} \underline{\varphi}}<\frac{-\frac{1}{1-\varepsilon} q_{e}^{\varepsilon} p_{e}^{1-\varepsilon}(\underline{\varphi})}{-\frac{1}{1-\varepsilon} q_{e}^{\varepsilon} p_{e}^{1-\varepsilon}\left(\varphi^{*}\right)}=\frac{p_{e}^{1-\varepsilon}(\underline{\varphi})}{p_{e}^{1-\varepsilon}\left(\varphi^{*}\right)}
$$

By plugging from (1) $p_{e}=\alpha \tau \varphi$, we get

$$
\frac{p^{1-\varepsilon}(\underline{\varphi})}{p^{1-\varepsilon}\left(\varphi^{*}\right)}=\frac{(\alpha \tau \underline{\varphi})^{1-\varepsilon}}{\left(\alpha \tau \varphi^{*}\right)^{1-\varepsilon}}=\frac{\underline{\varphi}^{1-\varepsilon}}{\varphi^{* 1-\varepsilon}}=\frac{\underline{\varphi} \cdot \underline{\varphi}^{-\varepsilon}}{\varphi^{*} \cdot \varphi^{*-\varepsilon}} .
$$

Now, since $\varphi^{*}>\underline{\varphi}$, we get

$$
\frac{\underline{\varphi} \cdot \underline{\varphi}^{-\varepsilon}}{\varphi^{*} \cdot \varphi^{*-\varepsilon}}<\frac{\varphi^{*} \cdot \underline{\varphi}^{-\varepsilon}}{\varphi^{*} \cdot \varphi^{*-\varepsilon}}=\frac{\underline{\varphi}^{-\varepsilon}}{\varphi^{*-\varepsilon}}
$$

This allows us to write

$$
\frac{\mathrm{d} \varphi^{*}}{\mathrm{~d} \varphi}<\frac{\underline{\varphi}^{-\varepsilon}}{\varphi^{*-\varepsilon}}
$$

and thus concludes the proof.

Lemma 3. For all values of parameters of the model, it always holds that

$$
\int_{\underline{\varphi}}^{\varphi^{*}} \frac{\partial x_{e}}{\partial \underline{\varphi}} \mathrm{d} \varphi>0
$$

The proof is based on the statement that $\frac{\partial x_{e}}{\partial \underline{\varphi}}>0$ shown as follows and on the fact that a definite integral of a positive function has to be positive.

Let us recall from (2) that

$$
x_{e}=(\alpha \varphi \tau)^{-\varepsilon} C q_{e}^{\varepsilon-\eta}
$$

where the only variable that depends on $\underline{\varphi}$ is the price index $q_{e}$, defined by (3) as 


$$
q_{e}=\left(\int_{\underline{\varphi}}^{\varphi^{*}} p_{e}^{1-\varepsilon}(\varphi) \mathrm{d} \varphi\right)^{\frac{1}{1-\varepsilon}}
$$

Hence,

$$
\frac{\partial x_{e}}{\partial \underline{\varphi}}=(\alpha \varphi \tau)^{-\varepsilon} C(\varepsilon-\eta) q_{e}^{\varepsilon-\eta-1} \frac{\partial q_{e}}{\partial \underline{\varphi}}
$$

Since by assumption $\varepsilon>\eta$, it holds that $(\alpha \varphi \tau)^{-\varepsilon} C(\varepsilon-\eta) q_{e}^{\varepsilon-\eta-1}>0$.

We can express

$$
\begin{aligned}
\frac{\partial q_{e}}{\partial \underline{\varphi}} & =\frac{\partial}{\partial \underline{\varphi}}\left(\left(\int_{\underline{\varphi}}^{\varphi^{*}} p_{e}^{1-\varepsilon}(\varphi) \mathrm{d} \varphi\right)^{\frac{1}{1-\varepsilon}}\right) \\
& =\frac{1}{1-\varepsilon}\left(\int_{\underline{\varphi}}^{\varphi^{*}} p_{e}^{1-\varepsilon}(\varphi) \mathrm{d} \varphi\right)^{\frac{\varepsilon}{1-\varepsilon}}\left(-p_{c}^{1-\varepsilon}(\underline{\varphi})\right) \\
& =\frac{1}{\varepsilon-1}\left(\int_{\underline{\varphi}}^{\varphi^{*}} p_{e}^{1-\varepsilon}(\varphi) \mathrm{d} \varphi\right)^{\frac{\varepsilon}{1-\varepsilon}} p_{e}^{1-\varepsilon}(\underline{\varphi})>0,
\end{aligned}
$$

which concludes the proof.

Theorem 1. When the elasticity of substitution among the varieties of the exported good is close enough to the elasticity of demand for these goods, then the entry of multinational firms in the industry will increase overall exports:

$$
\frac{\mathrm{d} E}{\mathrm{~d} \underline{\varphi}}<0 \quad \text { if } \quad \varepsilon \rightarrow \eta .
$$

Proof. Let us recall the definition (4):

$$
E=\int_{\underline{\varphi}}^{\varphi^{*}} x_{e}(\varphi) \mathrm{d} \varphi
$$

in which we can plug from (2) $x_{e}(\varphi)=(\alpha \varphi \tau)^{-\varepsilon} C q_{e}^{\varepsilon-\eta}$, obtaining 


$$
E=(\alpha \tau)^{-\varepsilon} C \int_{\underline{\varphi}}^{\varphi^{*}} \varphi^{-\varepsilon} \mathrm{d} \varphi q_{e}^{\varepsilon-\eta}
$$

Using the definition of the price index (3)

$$
q_{e}=\left(\int_{\underline{\varphi}}^{\varphi^{*}} p_{e}^{1-\varepsilon}(\varphi) \mathrm{d} \varphi\right)^{\frac{1}{1-\varepsilon}}
$$

and the expression (1)

$$
p_{e}=\alpha \tau \varphi
$$

we can reduce to

$$
E=K I_{1} I_{2}^{\frac{\varepsilon-\eta}{1-\varepsilon}}
$$

where

$$
K=C(\alpha \tau)^{-\varepsilon}>0, I_{1}=\int_{\underline{\varphi}}^{\varphi^{*}} \varphi^{-\varepsilon} \mathrm{d} \varphi \text { and } I_{2}=\int_{\underline{\varphi}}^{\varphi^{*}} \varphi^{1-\varepsilon} \mathrm{d} \varphi .
$$

Using this notation, we can express

$$
\frac{\mathrm{d} E}{\mathrm{~d} \underline{\varphi}}=K\left(\frac{\mathrm{d} I_{1}}{\mathrm{~d} \underline{\varphi}} I_{2}^{\frac{\varepsilon-\eta}{1-\varepsilon}}+I_{1} \frac{\varepsilon-\eta}{1-\varepsilon} I_{2}^{\frac{\varepsilon-\eta}{1-\varepsilon}}-1 \frac{\mathrm{d} I_{2}}{\mathrm{~d} \underline{\varphi}}\right)
$$

It is simple to find that

$$
\frac{\mathrm{d} I_{1}}{\mathrm{~d} \underline{\varphi}}=\varphi^{*-\varepsilon} \frac{\mathrm{d} \varphi^{*}}{\mathrm{~d} \underline{\varphi}}-\underline{\varphi}^{-\varepsilon} \text { and } \frac{\mathrm{d} I_{2}}{\mathrm{~d} \underline{\varphi}}=\varphi^{* 1-\varepsilon} \frac{\mathrm{d} \varphi^{*}}{\mathrm{~d} \underline{\varphi}}-\underline{\varphi}^{1-\varepsilon} .
$$

We know already from the proof of Lemma 2 that both these expressions are negative. Further, we know that $I_{1}>0$ and $I_{2}>0$, and hence the first term in parentheses in (8) is negative whereas the second one is positive. Therefore, the whole expression is negative if the first term in parentheses outweights the second one. When the elasticity of substitution among the varieties of the exported good is close enough to the elasticity of demand for these goods, i.e., when $\varepsilon \rightarrow \eta$, this condition is satisfied, which concludes the proof. 
Theorem 2. Let us model the spillover effect by $\frac{d \tau(\underline{\varphi})}{d \underline{\varphi}}>0$. When we denote by $E$ overall exports disregarding the possible spillover effect and by $E_{s}$ overall exports taking into account the spillover effect is, then for all values of the parameters of the model, it holds that

$$
\frac{\mathrm{d} E_{S}}{\mathrm{~d} \underline{\varphi}}<\frac{\mathrm{d} E}{\mathrm{~d} \underline{\varphi}}
$$

Proof. Similarly as in the proof of Theorem 1, we can write

$$
E_{s}=K(\underline{\varphi}) I_{1} I_{2}^{\frac{\varepsilon-\eta}{1-\varepsilon}}
$$

where

$$
K(\underline{\varphi})=C(\alpha \tau(\underline{\varphi}))^{-\varepsilon}>0, I_{1}=\int_{\underline{\varphi}}^{\varphi^{*}} \varphi^{-\varepsilon} \mathrm{d} \varphi \text { and } I_{2}=\int_{\underline{\varphi}}^{\varphi^{*}} \varphi^{1-\varepsilon} \mathrm{d} \varphi .
$$

We can write the derivative as

$$
\begin{aligned}
\frac{\mathrm{d} E_{s}}{\mathrm{~d} \underline{\varphi}} & =\frac{\mathrm{d} K(\underline{\varphi})}{\mathrm{d} \underline{\varphi}} I_{1} I_{2}^{\frac{\varepsilon-\eta}{1-\varepsilon}}+K(\underline{\varphi})\left(\frac{\mathrm{d} I_{1}}{\mathrm{~d} \underline{\varphi}} I_{2}^{\frac{\varepsilon-\eta}{1-\varepsilon}}+I_{1} \frac{\varepsilon-\eta}{1-\varepsilon} I_{2}^{\frac{\varepsilon-\eta}{1-\varepsilon}-1} \frac{\mathrm{d} I_{2}}{\mathrm{~d} \underline{\varphi}}\right) \\
& =\quad-\varepsilon C(\alpha \tau(\underline{\varphi}))^{-\varepsilon-1} \frac{\mathrm{d} \tau(\underline{\varphi})}{\mathrm{d} \underline{\varphi}}+\frac{\mathrm{d} E}{\mathrm{~d} \underline{\varphi}} .
\end{aligned}
$$

Since $\varepsilon>1$, the first term in this expression is always negative, which concludes the proof.

Theorem 3. Let us model the spillover effect by $\frac{d F_{e}(\underline{\varphi})}{d \underline{\varphi}}>0$. When we denote by $E$ overall exports disregarding the possible spillover effect and by $E_{s}$ overall exports taking into account the spillover effect is, then for all values of the parameters of the model, it holds that

$$
\frac{\mathrm{d} E_{S}}{\mathrm{~d} \underline{\varphi}}<\frac{\mathrm{d} E}{\mathrm{~d} \underline{\varphi}}
$$

Similarly as in (7), we can write 


$$
\frac{\mathrm{d} E_{s}}{\mathrm{~d} \underline{\varphi}}=x_{e}\left(\varphi^{*}\right)\left(\frac{\mathrm{d} \varphi^{*}}{\mathrm{~d} \underline{\varphi}}\right)_{s}-x_{e}(\underline{\varphi})+\int_{\underline{\varphi}}^{\varphi^{*}} \frac{\partial x_{e}}{\partial \underline{\varphi}} \mathrm{d} \varphi .
$$

The only difference with respect to (7) lies in the term $\left(\frac{\mathrm{d} \varphi^{*}}{\mathrm{~d} \underline{\underline{ }}}\right)_{S}$, because as we can see from all previous derivations, this is the only one in which $F_{e}$ plays any role.

We want to prove that

$$
\left(\frac{\mathrm{d} \varphi^{*}}{\mathrm{~d} \underline{\varphi}}\right)_{s}<\frac{\mathrm{d} \varphi^{*}}{\mathrm{~d} \underline{\varphi}}
$$

To do so, we would need to repeat the proof of Lemma 1, taking into account that now

$$
A=\frac{F_{e}(\underline{\varphi})^{\frac{1}{\varepsilon-\eta}}}{\left(\tau^{1-\varepsilon}(\alpha-1) \alpha^{-\varepsilon} C\right)^{\frac{1}{\varepsilon-\eta}}}=B \cdot F_{e}(\underline{\varphi})^{\frac{1}{\varepsilon-\eta}},
$$

where by $B$ we denote a positive constant.

Therefore

$$
\begin{aligned}
& \left(\frac{\mathrm{d} \varphi^{*}}{\mathrm{~d} \underline{\varphi}}\right)_{S}=\frac{-\frac{1}{\varepsilon-\eta} B F_{e}^{\frac{1}{\varepsilon-\eta}-1} \frac{\mathrm{d} F_{e}(\underline{\varphi})}{\mathrm{d} \underline{\varphi}}-\frac{1}{1-\varepsilon} q_{e}^{\varepsilon} p_{e}^{1-\varepsilon}(\underline{\varphi})}{\frac{\varepsilon-1}{\varepsilon-\eta} A \varphi^{* \frac{\eta-1}{\varepsilon-\eta}}-\frac{1}{1-\varepsilon} q_{e}^{\varepsilon} p_{e}^{1-\varepsilon}\left(\varphi^{*}\right)} \\
& =\frac{-\frac{1}{\varepsilon-\eta} B F_{e}^{\frac{1}{\varepsilon-\eta}-1} \frac{\mathrm{d} F_{e}(\underline{\varphi})}{\mathrm{d} \underline{\varphi}}}{\frac{\varepsilon-1}{\varepsilon-\eta} A \varphi^{* \frac{\eta-1}{\varepsilon-\eta}}-\frac{1}{1-\varepsilon} q_{e}^{\varepsilon} p_{e}^{1-\varepsilon}\left(\varphi^{*}\right)}+\frac{\mathrm{d} \varphi^{*}}{\mathrm{~d} \underline{\varphi}} .
\end{aligned}
$$

The fact that the denominator in this expression is positive and the assumption $\varepsilon>\eta$ then conclude the proof. 